\title{
Phototherapy and the use of heat shields in very low birthweight infants
}

\author{
P R STUTCHFIELD, N MODI, AND A M WEINDLING \\ Regional Neonatal Unit, Liverpool Maternity Hospital, Liverpool
}

SUMMARY The irradiance produced by phototherapy units in use on a neonatal unit was measured. The phototherapy tubes were found to decline at a variable rate. Heat shields used to decrease heat and evaporative losses in the very low birthweight infant reduce irradiance and may appreciably limit the effectiveness of phototherapy.

Phototherapy is an accepted treatment for neonatal hyperbilirubinaemia and reduces the need for exchange transfusions. 'A dose response relationship has been established with a peak response observed to blue light with a spectral range $420-470 \mathrm{~nm}$. A saturation point exists (between 1 and $3 \mathrm{~mW} / \mathrm{cm}^{2}$ ) beyond which further increases in irradiance do not produce further increases in the rate of fall of serum bilirubin. ${ }^{23} \mathrm{~A}$ minimum irradiance of $1 \mathrm{~mW} / \mathrm{cm}^{2}$ in the $420 / 480 \mathrm{~nm}$ range has been recommended to produce an optimum effect. ${ }^{3}$

Irradiance from phototherapy decreases with time due to the natural decay of the fluorescent bulbs. There is a sharp drop during the first 72 hours of use. In 200 hours, $20 \%$ or more of the irradiance in the blue wavelength may be lost. Recommendations for bulb replacement vary from 200 to 2000 hours. $^{4}$

Transparent thermal blankets, plastic hoods, and perspex heat shields are widely used to reduce heat and evaporative losses in the very low birthweight infant $(<1000 \mathrm{~g}) .^{56}$ The extent to which these coverings reduce the irradiance reaching these infants has not been reported.

This study was established to assess the output of phototherapy units currently in use on a regional neonatal intensive care unit and to determine the effect on irradiance of measures to reduce evaporative and heat losses.

\section{Methods}

Seven Vickers Medical phototherapy units were in use at the time of the study. Each was fitted with four 40 watt Vickers Medical blue $600 \mathrm{~mm}$ tubes. These had been changed six months before the start of the study. Digital clocks had been fitted to each unit allowing the hours of use to be calculated. The number of phototherapy hours of each phototherapy unit since the last change of bulbs was recorded.

Each unit was set up over an incubator (Vickers Medical Model 79). The distance between the phototherapy tubes and the mattress was measured. The irradiance produced by each unit was recorded on three occasions using an irradiance meter (MaCam R450). The optical detector of the irradiance meter was a solid state photodiode with optical filters with a spectral response matching the bilirubin phototherapy action spectrum between $430-475 \mathrm{~nm}$. The detector head had been modified with a cosine corrected diffuser giving a $180^{\circ}$ field of view. The sensor had a peak sensitivity at $450 \mathrm{~nm}$ and half maximum sensitivities at 429 and $475 \mathrm{~nm}$. The range of measurements was from 0 to 1.2 $\mathrm{mW} / \mathrm{cm}^{2}$. The top of the optical detector was $4 \mathrm{~cm}$ above the base of the irradiance meter at a similar height above the mattress as the body surface of the preterm infant. Calibration was checked by a standard that had been calibrated to the specifications of the United States National Bureau of Standards.

The irradiance meter was placed on the mattress in the incubator and its position adjusted to give an optimum recording. After recording the peak irradiance produced by each phototherapy unit the bulbs were renewed and the irradiance compared.

A thin plastic sheet, a plastic bubble blanket (thermal blanket) designed for industrial packing, and a clear perspex plastic headbox $(26 \mathrm{~cm} \times 26$ $\mathrm{cm} \times 15 \mathrm{~cm}$ ) all used as heat shields, were compared by placing each over the top of the optical detector of the radiometer and measuring the irradiance reaching an infant.

\section{Results}

The irradiance produced by each phototherapy unit was found to increase to a peak value 60-90 seconds after starting phototherapy. A progressive reduction in irradiance was observed when the output of six phototherapy units was then recorded at 15 minute intervals for two hours. A steady state was reached at a mean time of 45 minutes (range 30-90 minutes) after the start of phototherapy with no further reduction over a 24 hour period. The irradiance 
produced showed a mean (SD) reduction of $24 \%$ $(0.5)$ from the initial peak recording. After allowing the phototherapy bulbs to cool after disconnection of the units, the irradiance increased to the previous peak levels.

The number of phototherapy hours recorded on each unit varied from 1382 to 2499 hours. There was no correlation with peak irradiance produced $(\mathrm{r}=-0.56 \mathrm{p}>0.05)$. The peak irradiance recorded varied from 0.24 to $0.53 \mathrm{~mW} / \mathrm{cm}^{2}$ (table 1). On renewing the phototherapy tubes, the irradiance increased from 0.5 to 3.7 times as shown. The distance from the phototherapy unit bulbs to the mattress was 42 to $43 \mathrm{~cm}$ for all units except 1 and 7 . The stands of these two units were taller increasing the distance to $51 \mathrm{~cm}$. The irradiance produced by these units reached 0.58 and $0.64 \mathrm{~mW} / \mathrm{cm}^{2}$ only, after the change of tubes. When these units were lowered to $43 \mathrm{~cm}$ the irradiance increased by $50 \%$ and $60 \%$, respectively.

The effect of the heat shields on the irradiance reaching an infant was measured in triplicate, two hours after starting phototherapy. The reduction in irradiance recorded with each covering, using each phototherapy unit, was expressed as a percentage of the steady state irradiance. The mean was calculated and the effect of the coverings compared (table 2). The perspex heat shield and single layer plastic sheet

Table 1 Phototherapy hours and peak irradiance recorded from seven phototherapy units in current use and peak irradiance achieved with new tubes

\begin{tabular}{llll}
\hline $\begin{array}{l}\text { Phototherapy } \\
\text { unit No }\end{array}$ & $\begin{array}{l}\text { Time } \\
\text { (hours) }\end{array}$ & $\begin{array}{l}\text { Peak } \\
\text { irradiance } \\
\text { mW/cm }\end{array}$ & $\begin{array}{l}\text { Irradiance of } \\
\text { new phototherapy } \\
\text { tubes } \\
\text { mW/cm }\end{array}$ \\
\hline 1 & 1382 & $0 \cdot 24$ & 0.58 \\
2 & 1626 & 0.50 & 1.00 \\
3 & 1800 & 0.48 & 0.92 \\
4 & 2217 & 0.53 & 0.86 \\
5 & 2390 & 0.46 & 0.98 \\
6 & 2462 & $0 \cdot 28$ & 1.04 \\
7 & 2499 & 0.42 & 0.64 \\
\hline
\end{tabular}

Table 2 Reduction of steady state irradiance (mean percent $(S D)$ ) of six phototherapy units after optical detector of irradiance meter covered by a heat shield

\begin{tabular}{lrll}
\hline & \multicolumn{1}{c}{ Single } & Double & Quadruple \\
\hline Plastic sheet & $7 \cdot 0(0 \cdot 8)$ & $12 \cdot 5(0 \cdot 8)$ & $23 \cdot 1(1 \cdot 2)$ \\
Thermal blanket & $11.4(1 \cdot 3)$ & $19 \cdot 4(1 \cdot 2)$ & - \\
Perspex heat shield & $5 \cdot 3(1 \cdot 1)$ & - & - \\
Plus plastic sheet & $11.4(1 \cdot 0)$ & $17 \cdot 0(0 \cdot 8)$ & - \\
Plus thermal blanket & $16.9(1 \cdot 8)$ & $25 \cdot 1(1.7)$ & - \\
\hline
\end{tabular}

had less effect than the thermal blanket in which an $11.4 \%$ reduction in irradiance was observed. When a perspex heat shield in addition to a double layer of plastic or bubble sheet was used, a $17 \%$ and $25 \%$ reduction in irradiance was recorded, respectively.

\section{Discussion}

A considerable variation in the irradiance produced by the phototherapy units was found. The peak irradiance recorded from two of these units, No 1 and 6 , was minimal $\left(0 \cdot 24\right.$ and $0.28 \mathrm{~mW} / \mathrm{cm}^{2}$, respectively). There was no correlation with the hours of use; this shows the variable rate of decay of the blue phototherapy tubes. These tubes emit substantially more energy across the $425-475 \mathrm{~nm}$ wavelengths than broad spectrum bulbs. However, they are known to decay faster. The irradiance of two of the phototherapy units was decreased because of the increased distance of the bulbs from the mattress and a simple adjustment corrected this. Reducing the distance between phototherapy tubes and infant has been shown to increase the effectiveness of phototherapy. ${ }^{3}$

Measures to reduce heat and evaporative losses in the low birthweight infant may reduce the effectiveness of phototherapy. A reduction in the steady state irradiance by $5.3 \%$ was recorded with a perspex heat shield, $7 \%$ with a single plastic sheet, and $11.4 \%$ with a thermal blanket. Where difficulty in maintaining body temperature is encountered there is a tendency to increase the number of plastic layers. This reduces the irradiance further. A reduction of $25 \cdot 1 \%$ of the steady state irradiance was observed if a double thermal blanket plus perspex shield was used. Depending on the output of the phototherapy unit used, such reductions may appreciably alter the effectiveness of the phototherapy.

The sick extremely low birthweight infant $(<1000$ $\mathrm{g})$ is particularly at risk from hyperbilirubinaemia. With the complications and hazards of exchange transfusions it is important that the phototherapy treatment available for any neonate is optimal. The output of all phototherapy units should periodically be checked and the above factors relating to its use taken into consideration.

\footnotetext{
References

' Brown AK, Kim MH, Wu PYK, Bryla DA. Efficacy of phototherapy in prevention and management of neonatal hyperbilirubinaemia. Pediatrics 1985:75(suppl):393-400.

2 Tan KL. The pattern of bilirubin response to phototherapy for neonatal hyperbilirubinaemia. Pediatr Res 1982;16:670-4.

${ }^{3}$ Modi N, Keay AJ. Phototherapy for neonatal hyperbilirubi-
} 
naeamia: the importance of dose. Arch Dis Child 1983;58: 406-9.

${ }^{4}$ Characteristics of fluorescent bulbs used in neonatal phototherapy. Olympic Medical Technical Bulletin. (BN-04A.)

${ }^{5}$ Marks KH, Friedman Z, Maisels MJ. A simple device for reducing insensible water loss in low birthweight infants. Pediatrics 1977;60:223-6.

${ }^{6}$ Baumgart S, Fox WW, Polin RA. Physiologic implications of two different heat shiclds for infants under radiant warmers. J Pediatr 1982;100:787-90.

Correspondence to Dr PR Stutchfied, University of Liverpool, Institute of Child Health, Royal Liverpool Children's Hospital Alder Hey, Eaton Road, Liverpool L12 2AP.

Accepted 30 November 1987

\title{
Gall bladder distention in newborns
}

\author{
R P CORBETT AND J R EGNER
}

Department of Paediatrics, Addington Hospital and University of Natal, Durban, South Africa

SUMmaRY Three cases of gall bladder distention in asphyxiated newborns are described. Clinical and ultrasound examination showed this to be a benign, transient phenomenon. A causal relation between tissue hypoxia and gall bladder distention is proposed.

Gall bladder distention in neonates has only recently been described by several authors, ${ }^{1-6}$ but considerable conjecture regarding the pathophysiology of this finding exists as reflected by the numerous hypotheses proposed. Lack of enteral feeding, ${ }^{2.3}$ sepsis ${ }^{4}$ hepatic vein engorgement, ${ }^{5}$ and transient functional disturbance of gall bladder motility ${ }^{6}$ have all been implicated as causes of gall bladder distention.

Transient gall bladder distention occurring in three asphyxiated neonates is described and an hypothesis linking this phenomenon with tissue hypoxia is proposed.

\section{Case reports}

Case 1. An asphyxiated boy, weighing $4100 \mathrm{~g}$, was delivered by caesarean section at 42 weeks' gestation. Apgar scores were 3 and 4 at one and five mintues, respectively. The initial blood $\mathrm{pH}$ was $7 \cdot 16$ with a base deficit of $12 \cdot 2$. The immediate neonatal course was complicated by seizures, acute tubular necrosis, ileus, and urinary retention. On the third postnatal day, a large, firm mass was palpated in the right hypochondrium extendings to below the level of the umbilicus. Ultrasound examination showed a distended gall bladder measuring $4.6 \times 2 \mathrm{~cm}$ (fig 1 ). Nasogastric feeds of expressed breast milk were introduced on the fourth postnatal day. The mass remained palpable until the 13th day. A repeat ultrasound examination on day 11 confirmed resolu- tion of the enlargement. An unconjugated hyperbilirubinaemia was prolonged, but not severe. Blood cultures were sterile.

Case 2. A boy, weighing $2350 \mathrm{~g}$, was delivered by caesarean section after fetal distress at 36 weeks gestation. The Apgar scores were not accurately recorded, but the blood $\mathrm{pH}$ was 7.09 and base deficit 14.5. There was no conclusive evidence for acute tubular necrosis, ileus, or urinary retention. The infant was severely hypotonic, however, and remained so during the period of hospital care. A firm, regular mass was palpated in the right hypochondrium on the third day. Ultrasound examination showed a distended gall bladder measuring $4 \times 1.3 \mathrm{~cm}$ (fig 2 ). The mass was not clinically

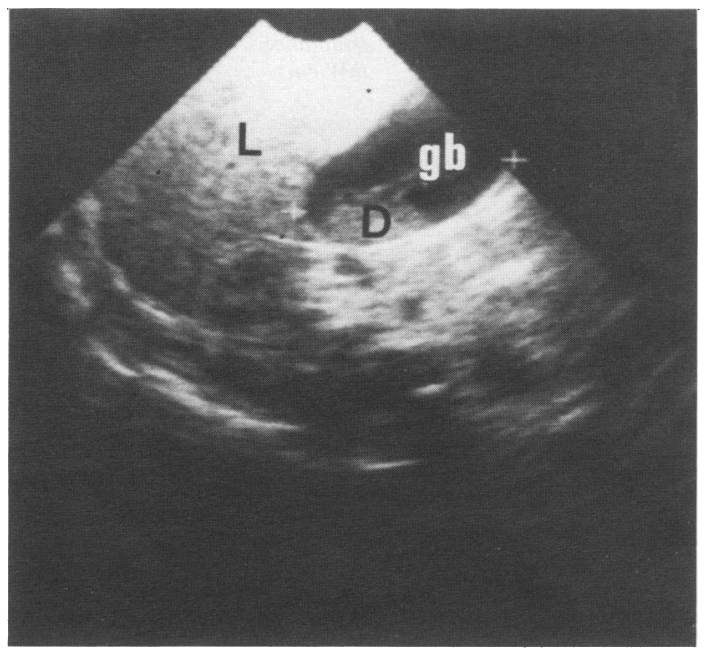

Fig 1 Ultrasound picture taken on third postnatal day showing distended gall bladder containing debris in case 1. ( $L=$ liver, gb=gall bladder, and $D=$ debris). 